\title{
Astrologia zodiacal: \\ o simbolismo como fundamento da cosmologia
}

\author{
Bruno Bertolossi de Carvalho* \\ Recibido: 20 de noviembre de 2016 \\ Enviado a pares evaluadores: 15 de diciembre de 2016 \\ Aprobado por pares evaluadores: 18 de enero de 2017 \\ Aprobado por comité editorial: 28 de febrero de 2017 \\ D0l: 10.22395/csye.v6n11a6
}

\section{RESUMO}

Este estudo é uma contribuição para a pesquisa antropológica sobre a astrologia zodiacal, apresentando uma reflexão sobre as consequências lógicas do simbolismo como pressuposto metafísico. Tal ideia impõe um tipo específico de fundamentação do sistema astrológico e que este desempenhe o papel de base da cosmologia pressuposta pelos astrólogos diante de qualquer objeto. Acompanhando um trabalho de campo sobre o tema, este artigo se concentra na justificação de sua hipótese através de entrevistas com três astrólogos, orientado metodologicamente por uma concepção hermenêutica da antropologia.

Palavras-chave: astrologia, Ssstema classificatório, visão de mundo, cosmologia, hermenêutica.

Bacharel em Antropologia, Universidade Estadual de Campinas (UNICAMP). Estudante, Mestrado em Filosofia, Universidad de Caldas. O autor trabalha independente com reflexões sobre formação, política, filosofia e teologia. Publica no seu website: http://brunobertolossidecarvalho.org. Correo electrónico: brunobertolossicarvalho@gmail.com 


\section{Zodiacal astrology: the symbolism as the basis of cosmology}

\section{ABSTRACT}

This study is a contribution to the anthropological research on zodiac astrology, presenting a reflection on the logical consequences of the symbolism as a metaphysical assumption. Such idea requires a specific type of grounding of astrological system and that it performs a base role in astrologists cosmology assumptions on

any subject. As a part of a field work on that topic, this article concentrates on justifying its hypothesis through interviews with three astrologists, methodologically built towards a hermeneutic conception of anthropology.

Keywords: astrology, classificatory system, world view, cosmology, hermeneutics. 


\section{Introdução}

A pesquisa que originou este artigo começou com a participação em um curso de astrologia em São Paulo. Além da oportunidade de aprender os conceitos básicos da teoria astrológica, tal experiência possibilitou constatações importantes a respeito do campo que deveria ser compreendido. Através das aulas e do contato com os demais alunos, foi alcançado um maior entendimento do que significa pensar astrologicamente, enquanto forma específica de conceber a realidade.

Porém, algo que manifestou características fundamentais do objeto foi um elemento inicialmente surpreendente e que se tornou determinante para os rumos deste trabalho. A professora Camila Jabur, astróloga formada em filosofia e que também atua como terapeuta, utiliza um livro que desenvolve temas da obra de Heidegger (Van de Beuque, 2004) como introdução para suas aulas. Portanto, a filosofia heideggeriana é marcante na perspectiva de Camila sobre a astrologia. Ela ainda recorre a vários outros conteúdos não astrológicos ao longo do curso, como, por exemplo, alguns textos de psicanalistas como Winnicott e Gilberto Safra.

Já na literatura astrológica, foi observada uma frequente referência a ideias de Jung, como sincronicidade, tipos psicológicos, sombra, arquétipos e inconsciente coletivo. A influência da teoria junguiana sobre adeptos da astrologia já havia sido observada por Vilhena (1990). Assim, esta presença comum de noções não originárias do sistema zodiacal na prática astrológica, foi a questão observável que desafiou a elaboração de uma hipótese que permitisse um aprofundamento do conhecimento sobre o tema estudado.

O contato com o campo contou também com a leitura do mapa astral do pesquisador feita pela astróloga Ciça Bueno. Dentro dos limites deste artigo, no entanto, serão comentadas apenas entrevistas abertas com três astrólogos de São Paulo, as já citadas Camila Jabur e Ciça Bueno, assim como Rui Barros, que representam pontos de vista paradigmáticos para o desenvolvimento da problemática que conduziu o trabalho. ${ }^{1}$

\footnotetext{
1 Como já mencionado, Camila atua profissionalmente tanto como astróloga quanto como terapeuta e é formada em filosofia. Ciça também trabalha como astróloga, escreve artigos em seu site e é formada em música. Rui não atende mais clientes como astrólogo atualmente, dedicando-se a textos com análises no campo da astrologia mundial, voltada para fenômenos sociais, políticos e econômicos dos países. Ele é historiador e sua dissertação de mestrado em História Social chama-se "Tomando o céu de assalto. Esoterismo, ciência e sociedade 1848-1914: França, Inglaterra e EUA". A formação e a atividade destes astrólogos são informações relevantes para a compreensão de seus pontos de vista sobre a astrologia. A exibição de suas identidades foi autorizada.
} 


\section{Problemática}

Continuidade e descontinuidade caracterizam a astrologia zodiacal ao longo de sua história, segundo Vilhena (1990). Este antropólogo, ao investigar até que ponto ela contribui para a formação de determinada cultura, a define como um único sistema classificatório permanente, pois seu modelo teórico foi estabelecido desde a antiguidade. E completa esta hipótese afirmando que sua fundamentação e utilidade são adaptáveis às visões de mundo próprias de cada contexto em que é praticada.

Assim, há estabilidade no postulado que relaciona o que existe e acontece na Terra aos movimentos e posições dos astros, mas também na estrutura classificatória que define os significados dos símbolos astrológicos e nos princípios que orientam as técnicas para interpretar as configurações encontradas em um mapa astral. Tais componentes proporcionam unidade estrutural à astrologia zodiacal e uma lógica própria, fiel à sistematização que recebeu no período helenístico, adquirindo a forma que vigora até hoje. Portanto, Vilhena (1990), afirma que há uma continuidade na trajetória da astrologia, mesmo que sempre praticada em contextos sincréticos, ligada a outros sistemas e a crenças de diversas origens. Por outro lado, ele considera que cada período histórico ou segmento social define seus fundamentos cosmológicos, sua utilização específica e sua ideologia, o que faz com que visões de mundo contrastantes possam se apropriar dela em cada caso, fornecendo diferentes explicações para sua eficácia e a empregando de modos diversos, embora enfrentem certas questões comuns.

Em sua pesquisa, cujo campo envolveu um grupo dedicado ao estudo da astrologia na zona Sul do Rio de Janeiro, a visão de mundo é caracterizada por três componentes principais. A ideia metafísica central, à qual se apela como justificativa lógica do modo de raciocinar próprio dos astrólogos, é definida por Vilhena (1990) como simbolismo, sem o qual um mapa astrológico natal, a noção dinâmica de trânsitos, assim como toda e qualquer técnica de interpretação desde a perspectiva zodiacal perdem o sentido e a validade. Pelo evidente contraste ao lado da racionalidade científica moderna, na qual a causalidade se restringe ao plano material em que corpos agem uns sobre outros, apoiar-se no simbolismo leva a um conflito com a cultura hegemônica presente, de acordo com o entendimento dos próprios adeptos da astrologia. Rejeitar a modernidade criticamente e defender um saber tradicional torna-se uma atitude essencial. Além disso, há um individualismo marcante no interesse pelo estudo da teoria astrológica e em seu uso, que adquire no geral uma forma psicologizante, com ênfase no protagonismo da consciência e do auto-conhecimento como finalidade, havendo grande importância na auto-observação.

Já Defrance (1972), limita as formas de preenchimento dos pressupostos últimos -metafísicos e epistemológicos- da astrologia zodiacal a apenas duas 
possibilidades lógicas. Para uma visão de mundo racionalista-positivista, que envolve o desejo do reconhecimento como ciência, a astrologia deve ser explicada de acordo com a astrofísica. Nesta perspectiva, ela deve receber uma justificação física como a afirmação de que a modificação das configurações planetárias provoca efeito paralelo no campo magnético recorrendo à estatística para realizar uma verificação empírica das asserções dos horóscopos. Adepta, portanto, de uma noção de causalidade material, esta forma de astrologia busca instrumentos modernos para defender-se dos que a caracterizam como superstição.

No entanto, para uma visão de mundo mágico-panteísta, a astrologia não quer ser ciência e não precisa se legitimar epistemologicamente, pois é concebida como uma filosofia ou uma sabedoria antiga, cujas verdades e virtudes foram abandonadas pelo pensamento científico moderno. Rejeitando a noção de causalidade, esta perspectiva apresenta a reciprocidade analógica como base de suas explicações, sendo astros e homens os sinais de uma ordem simbólica subjacente ao cosmos como um todo. As analogias permitem encontrar correspondências entre setores diversos da realidade, estabelecendo símbolos que expressam uma unidade de tudo que existe. Tais perspectivas divergentes não constituem duas escolas, mas tendências permanentes resultantes da própria lógica da astrologia e que revelam choques e oscilações entre dois tipos de visão de mundo (Defrance, 1972).

Após apresentar os signos do Zodíaco como um sistema de classificação similar aos sistemas ditos totêmicos, Costa (2007) menciona as premissas básicas que revelam a lógica que estrutura o sistema astrológico. Todas as coisas existentes no mundo são divididas entre domínios astrológicos, pois estão relacionadas aos astros, de acordo com a ideia de simpatias. Assim, a astrologia opera de forma multidimensional já que cada conteúdo empírico é entendido como extensão coerente de categorias astrológicas fundamentais, o que permite que qualquer problema seja investigado por ela. Portanto, trata-se de um sistema totalizante que pode abarcar todas as áreas de conhecimento.

\section{Objetivos e metodologia}

Da pesquisa de Vilhena (1990), será mantida a divisão da astrologia entre fundamentação, utilidade e estrutura classificatória, para que se direcione a atenção ao problema empírico da relação entre este sistema classificatório e visões de mundo diversas. Porém, a hipótese proposta por tal autor será reformulada a partir de uma reflexão sobre os conceitos nela articulados, em diálogo com os trabalhos de Defrance (1972) e Costa (2007). A hipótese aqui defendida norteia a realização das entrevistas utilizadas e o exame do conteúdo que elas evidenciam. 
Durkheim (2008) utiliza a expressão sistema cosmológico do totemismo, pois afirma que ele fornece uma concepção do universo ou uma representação total do mundo, podendo ser considerado uma espécie de filosofia da natureza (Durkheim \& Mauss, 1998). Assim, deve ser enfatizado que em um sistema classificatório, os seres e fatos são concebidos sob a forma de grupos coordenados e subordinados uns aos outros, ou seja, são ordenados de acordo com um plano unitário. A totalidade das coisas do universo forma um só conjunto, cujos grupos não estão isolados uns dos outros, mas possuem relações definidas. É um sistema de noções hierarquizadas e funciona como uma classificação sistemática que abarca toda a natureza. Seu fim é especulativo e serve para unificar o conhecimento, ao ligar as ideias entre si e tornar inteligíveis as relações entre os seres. Definidos conceitos fundamentais, como a noção capital de totem, é necessário situar todos os conhecimentos em relação a eles, ligando-os às noções formuladas a respeito de outras coisas. Posteriormente, Lévi-Strauss (1989) desenvolve a ideia de uma lógica de diferenças e semelhanças que liga séries descontínuas, sendo a extensão ilimitada inerente a um sistema classificatório.

A visão de mundo é o quadro que contém as ideias mais abrangentes sobre a ordem, como os conceitos de natureza, de humanidade e de sociedade que um povo possui (Geertz, 1989). É formada por concepções fundamentais sobre o todo, que perpassam o conjunto completo dos demais pensamentos e sentimentos sobre o mundo, influenciando o comportamento humano, o que indica semelhanças com outros conceitos antropológicos comuns, como o de cosmologia e o de ideologia (Rapport \& Overing, 2000).

Viveiros de Castro (1996) define a cosmologia como uma concepção ou imagem do mundo, formada por um conjunto mais ou menos coerente de representações, que estabelece os elementos componentes fundamentais do universo, ou seja, são noções e princípios que se referem à totalidade do existente e suas determinações últimas.

Considerando a caracterização dos conceitos em questão, a hipótese que este estudo defende é que o simbolismo (Vilhena, 1990) é a base que tanto sustenta o sistema zodiacal no funcionamento que lhe é próprio, como permite incorporar ilimitadamente outras categorias adquiridas por influência da cultura de cada contexto sócio-histórico, para articulá-las às categorias astrológicas, formando com coesão uma única cosmologia. O simbolismo assim elevado ao status de tese cosmológica fundamental coincide com a visão de mundo mágico-panteísta conforme Defrance (1972) e com a lógica da simpatia que permite caracterizar a astrologia como um sistema totalizante, segundo Costa (2007).

Por via da analogia, os múltiplos seres, fenômenos e objetos se unificam em uma ordem comum desde a perspectiva do simbolismo. Daí resulta como possibilidade que haja correspondência recíproca entre os elementos constitutivos 
de toda forma de realidade. Um planeta, uma constelação, animais ou deuses mitológicos, podem então combinar-se em estruturas abrangentes que fornecem significados para experiências humanas, características de personalidade e de comportamento. Além disso, o nível transcendente representado pelos símbolos astrológicos teria o poder de agir sobre o nível empírico da realidade.

Tal perspectiva leva a um sistema totalizante que generaliza a aplicação das categorias astrológicas a todos os domínios da realidade, possibilitando interpretar a partir delas o que se queira. Mesmo não impondo uma ideologia específica e sendo flexível quanto à finalidade de sua utilização, a astrologia é o horizonte mais abrangente da cosmologia de um astrólogo: as ideias astrológicas básicas são encontradas entre as concepções fundamentais às quais todas as demais noções precisam estar ligadas e situadas em sua perspectiva.

Sendo assim, a utilização de noções adquiridas a cada novo contexto pelo qual se expande a prática astrológica não representa uma alteração ao nível de seus pressupostos últimos. Pelo contrário, dá-se necessariamente como síntese produzida pela lógica constitutiva deste sistema teórico, que ao entrar em contato com outros esquemas de conceitos, os assimila sem colocar em risco sua coerência interna.

A hipótese formulada será avaliada através da interpretação das entrevistas, nas quais foram tratadas questões relativas às premissas básicas que explicam o funcionamento da astrologia e ao uso de noções oriundas de fontes externas ao sistema zodiacal na prática astrológica.

Para compreender o horizonte de sentido dos astrólogos, foram observadas as pressuposições, subentendidos e implicações lógicas contidas em suas formulações, para ampliar o que expõem as entrevistas até seu nível implícito. Tal horizonte é entendido como uma estrutura complexa de significados, ou seja, um sistema simbólico (Geertz, 1989). A apreensão desta estruturação permite compreender a arquitetônica de uma cosmologia cujo fundamento compartilhado por todos é o simbolismo, que perpassa todas as demais noções presentes em cada ponto de vista. Desta forma, pode ser constatado até que ponto vão as diferenças entre os entrevistados, assim como o que é inerente à astrologia zodiacal e precisa permanecer apesar de particularidades apresentadas no discurso de cada astrólogo.

\section{Entrevistas}

\section{Rui Barros ${ }^{2}$}

A astrologia funciona não por causa da força de gravitação, não por causa de uma radiação física qualquer. Como é que a astrologia funciona? Essa é uma questão. A

2 Entrevista gravada em São Paulo, 17/08/2012. 
resposta, para mim, está na cosmologia antiga. A astrologia é um fenômeno que se realiza no mundo intermediário e que tem repercussões no mundo físico, portanto não é nenhuma das forças ou energias que os físicos laboram.

Para Rui, após ter recebido sua estruturação mínima no mundo grego, a astrologia permaneceu com a mesma fundamentação até hoje, assim como os planetas, signos e casas ainda possuem os mesmos significados. O que se altera são as técnicas astrológicas, as quais, desde o início, passam por refinamento e transformações. Ele defende que, para uma compreensão correta, é necessário remeter o sistema zodiacal a uma antiga doutrina cosmológica, que ligava religião, filosofia, ciência e arte, e da qual a astrologia era um ramo especializado. Em tal cosmologia, a realidade era dividida em três mundos: celestial, intermediário e sensorial, estando todos estes presentes na composição de cada ser humano. Ciclos determinados caracterizavam estes domínios e havia uma concepção qualitativa de tempo. O âmbito onde ocorrem os fenômenos astrológicos é o mundo intermediário, que influencia os corpos e acontecimentos do mundo sensorial.

Porém, os antigos não chegaram a desenvolver uma teoria para explicar como isso se dá, apenas postulavam que tudo no cosmos está tão interligado que o mundo sub-lunar está ordenado de acordo com o modelo superior celeste, ou seja, que as coisas de baixo são guiadas pelas de cima. Rui então argumenta que a noção de correspondência entre os movimentos celestes e os acontecimentos na Terra estava mais próxima do conceito junguiano de sincronicidade do que de uma relação causal, pois os autores antigos jamais teorizaram a respeito de uma ação física à distância.

Portanto, para ele, os princípios astrológicos são metafísicos e a lógica da totalidade de componentes do sistema zodiacal é simbólica. Sua opinião é que isto impede qualquer diálogo com as ciências empíricas modernas - exclusivamente preocupadas com o mundo de forças e energias físicas - sendo impossível defender uma astrologia materialista que recorre a verificações estatísticas.

Há nesta perspectiva uma inversão da atribuição de continuidade e descontinuidade em comparação à hipótese de Vilhena (1990): para Rui, há uma permanência da fundamentação e são as técnicas que se alteram ao longo da história da astrologia. Além disso, defender que sempre houve a mesma fundamentação representa adotar posição favorável a uma concepção que se preocupa com a fidelidade à visão de mundo própria do contexto de origem do sistema zodiacal, contra vertentes que buscam alguma forma de adaptação à perspectiva positivista.

Deste modo, para o entrevistado, não se trata de um sistema flexível, cuja fundamentação poderia ser redefinida em cada contexto: ser ciência positiva 
não estaria entre as possibilidades da astrologia, mas isto representaria uma falta de compreensão sobre sua natureza.

Ter sido inicialmente parte de uma doutrina metafísica mais ampla é um elemento fundamental para a caracterização da astrologia. De um lado, é uma confirmação da pertinência do argumento de Vilhena (1990) de que a astrologia não fornece sozinha uma cosmologia completa, pois foi, desde o início, um ramo de sistemas mais abrangentes. Por outro lado, o sistema zodiacal dependia de pressupostos últimos específicos, definidos pela doutrina de que era parte: um universo constituído por três mundos caracterizados por ciclos e presentes na composição de cada ser humano, em que o tempo é concebido qualitativamente e todas as suas partes estão interligadas de modo a subordinar a realidade mundana ao movimento ordenado dos astros, o qual funciona como modelo ou sinal da estrutura cósmica como um todo. Por isso, deve-se analisar se tais pressupostos fundamentais são indispensáveis a cada explicação particular do funcionamento da astrologia independentemente de uma formulação explícita dos mesmos, ou se podem existir formas alternativas de fundamentá-la.

A aproximação entre as noções de sincronicidade e de correspondência envolve o entendimento de que ambas possuem em comum a concepção qualitativa do tempo e a crença em conexões localizadas em outro nível da realidade que não o da causalidade material. Não se trata evidentemente de uma visão de mundo orientada pela obra de Jung que se apropria do sistema astrológico esvaziando-o de seus fundamentos originários, mas de considerar que duas noções distintas se referem a um mesmo fenômeno. Portanto, um conceito moderno não altera necessariamente uma cosmologia antiga, mas pode subordinar-se a ela.

Quanto às diversas possibilidades imagináveis de aplicação da astrologia, Rui considera haver um critério claro:

A astrologia é uma linguagem abstrata que pode ser aplicada a muitas coisas, desde que você as conheça. Uma linguagem abstrata que se aplica ao corpo humano, à biologia e aos mais variados campos, mas para você falar com alguma razoabilidade deles, você precisa ter o conhecimento desses campos, conhecer o objeto.

Esta forma de definir a astrologia demonstra a suposição de uma coexistência de dois tipos de conhecimento. O saber puramente astrológico se refere a uma estrutura cósmica compartilhada pela totalidade do existente, mas as especificidades de cada fenômeno ou objeto devem ser descritas pelo conhecimento empírico produzido a partir de observações que independem de qualquer orientação astrológica. Mais do que reconhecido, o repertório científico existente deve guiar o uso da astrologia para que seja correto: não basta possuir um esquema que pode se referir a tudo, pois ele não informa as peculiaridades dos diversos domínios da realidade, sendo necessário saber como se adapta adequadamente 
a cada campo. Trata-se de um critério epistemológico para ordenar a expansão ilimitada do uso do sistema zodiacal, com seu potencial de se ajustar a lógicas diversas em cada nova aplicação.

A forma pela qual isso deve ser feito é exemplificada pela opinião de Rui a respeito do diálogo com a teoria de Freud:

É muito restrito, o ser humano é maior do que aquilo que ele descreve. Mas com certeza ele observou e descreveu mecanismos psicológicos que são reais. Portanto, use. "Espelho partido" 3 trata disso: como você pode usar determinadas configurações astrológicas e traduzir numa linguagem freudiana, ou vice-versa. Tem aproximações perfeitamentes úteis e necessárias.

Desde que um conhecimento empírico tenha validade, ele será útil para a prática astrológica, pois se considera que cada objeto possua essencialmente dois aspectos: as características que o tornam um ente particular e o que ele é quando inserido em uma totalidade da qual participa. O primeiro aspecto está na linguagem da psicologia, da medicina, da meteorologia, e assim por diante, enquanto do segundo trata a astrologia. Não são duas essências, nem uma essência com dois níveis, pois a linguagem científica pode ser traduzida para a astrológica e vice-versa. O que um objeto é segundo as ciências deve coincidir com o que ele é ao ser considerado astrologicamente, embora desta forma seja compreendido a partir de um horizonte mais abrangente. Por não se comportar como um modelo de conhecimento entre os outros, a astrologia busca abarcar os demais sistemas com que entra em contato, situando-os na estrutura cósmica que ela pressupõe.

\subsection{Ciça Bueno ${ }^{4}$}

Para Ciça, há uma comunhão entre o céu e a Terra que havia sido percebida inicialmente de forma animista, já que os mais antigos acreditavam estar lidando com os deuses.

Depois do Jung, a gente compreendeu tecnicamente a astrologia, que se baseia num fenômeno de percepção de que o céu e a Terra se sincronizam. Toda a questão é essa da atratividade ou da sincronia, pode chamar essa lei que rege a astrologia de lei da correspondência, ou da semelhança, o semelhante atrai o semelhante. E dentro disso tem vertentes. Mas pode se apoiar no Jung como teoria da sincronicidade, que consegue fundamentar bem o funcionamento da astrologia. Isso bastaria.

Aqui a noção de sincronicidade não é mencionada apenas como próxima, mas como equivalente à de correspondência, para explicar o funcionamento da astrologia. Ou, mais precisamente, a noção junguiana representa um passo a

3 O entrevistado cita uma publicação de sua autoria que pode ser verificada nas referências biliográficas.

4 Entrevista gravada em São Paulo, 22/08/2012. 
mais na elaboração teórica desta ideia já conhecida dos antigos, mas apenas agora compreendida tecnicamente. Novamente, ambas as noções, referem-se a um mesmo fenômeno. Assim, apesar de uma nova forma de explicação ser utilizada, ela estabelece que os mesmos pressupostos cosmológicos possam valer tanto para os antigos astrólogos quanto para Jung: um universo no qual o tempo é qualificado, em que existem conexões acausais entre os fenômenos e coincidências significativas. Portanto, apesar desta teoria psicológica fornecer uma nova elaboração para a explicação do funcionamento da astrologia, o conceito dela extraído está subordinado à cosmologia que sustentava a antiga noção de correspondência.

O uso de um princípio de explicação que considera conexões acausais, mais uma vez expressa uma compreensão simbólica da astrologia. O fato dos astros não se encontrarem fisicamente localizados no céu nas posições que os astrólogos consideram para suas interpretações é mencionado, o que torna esta perspectiva ainda mais coerente. Mas, ao mesmo tempo, Ciça admite acreditar na possibilidade de uma futura descoberta científica fornecer a explicação para uma causalidade física presente no funcionamento da astrologia. Ao referir-se à ciência, não realiza necessariamente uma adaptação da astrologia a uma visão de mundo moderna, pois as possibilidades de explicação simbólica ou causal resultam da própria lógica do sistema e, por isso, não geram duas escolas distintas, mas tendências permanentes (Defrance, 1972). Uma concepção pode conviver com a outra porque não se anulam necessariamente, estando ambas presentes na literatura astrológica.

A combinação com outros sistemas se dá através de um princípio consciente, o qual é elemento fundamental da lógica inerente à astrologia:

Um outro fenômeno que a gente usa muito é o da analogia, podendo associar outros conhecimentos para compreender a astrologia, desde geometria, psicologia, antropologia, pode ir associando, pensando o sistema solar como um macro-organismo e o ser humano como algo que vem abaixo disso, dentro de uma hierarquia da natureza.

O conceito de analogia manifesta a unidade do cosmos como base, com a resultante correspondência entre suas partes interligadas. De acordo com esta ideia, para Ciça, os planetas são funções psíquicas -sobretudo conforme a teoria junguiana- assim como, sob influência de Nietzsche, os planetas são forças, o que torna o mapa um jogo entre estas. Ela também menciona a concepção de karma, que estaria representado pelo planeta Saturno.

Definir planetas como funções psíquicas é consequência do processo de psicologização da astrologia, que ao longo do século XX reinterpretou conteúdos do mapa astrológico em termos de interioridade do sujeito. Tal fato não alterou os fundamentos cosmológicos do sistema, pois se trata apenas de um exemplo 
do funcionamento já descrito de um sistema classificatório, com sua capacidade de expansão. Com uma consideração mais minuciosa da subjetividade, surge um novo campo de fenômenos que a astrologia buscou assimilar, traduzindo o novo vocabulário para sua linguagem simbólica tradicional. A abordagem psicológica representa uma transformação significativa da astrologia, com uma ênfase em noções oriundas de uma visão de mundo moderna que, ainda assim, não altera os pressupostos metafísicos que tradicionalmente lhe servem de base.

O entendimento do mapa astrológico como um jogo de forças não é concebido como uma alteração: tal noção seria uma expressão do que ele sempre foi, ou uma elaboração maior de uma compreensão mais ou menos consciente que os astrólogos sempre tiveram ao interpretarem os mapas. Afinal, os planetas sempre foram compreendidos a partir das relações mantidas entre uns e outros, ou como um sistema.

Embora o karma seja uma noção esotérica recentemente acrescentada, a associação ao planeta Saturno ilustra a forma como conceitos provenientes de outras fontes culturais precisam ser posicionados na estrutura cósmica pressuposta pelo sistema zodiacal para que este os assimile. Assim também ocorre com as noções que orientam esta astróloga na leitura dos mapas:

Leio mapa partindo de duas premissas, que não são astrológicas, são minhas, é minha interpretação. A primeira delas: que você já teve outras vidas. A segunda: que você tem um projeto de vida, e o mapa é uma das maneiras de acessá-lo.

A reencarnação não é uma noção oriunda do sistema zodiacal, mas funciona como explicação eficaz para os casos em que mapas idênticos se referem a indivíduos com trajetórias e personalidades inteiramente diferentes: são gêmeos astrais, mas desiguais quanto às experiências acumuladas em vidas passadas. É uma noção não originária, mas adequada para a solução de um problema gerado pela própria prática astrológica: uma dimensão do indivíduo anterior ao seu nascimento e que, por isso, é mais fundamental que o próprio mapa natal e determina o rumo que os atributos astrológicos tomarão em cada caso. As configurações zodiacais não deixam de vigorar como mecanismos constitutivos da personalidade e fio condutor da existência, apenas abrem espaço para outro fator, o qual permite explicar diferentes resultados observáveis, remetendo-os a experiências em encarnações passadas.

A noção de projeto se articula com a de reencarnação e, mesmo sendo externa ao sistema, é uma elaboração que toma como ponto de partida a lógica astrológica. A finalidade de cada existência já está definida e registrada no momento do nascimento, afinal, o mapa natal é uma forma de ter acesso ao projeto. Além deste marco inicial ser mantido como chave para a compreensão de uma vida, os rumos que o destino individual toma efetivamente, assim como 
os que deveria tomar para alcançar os propósitos previamente estabelecidos, também se vinculam aos conteúdos presentes no mapa. A teleologia implicada nesta concepção pressupõe as configurações dos astros.

\subsection{Camila Jabur ${ }^{5}$}

O mistério como fundamento distingue o ponto de vista desta astróloga dos anteriores. Camila se dedica há anos a uma reflexão sobre a essência da astrologia, orientada, sobretudo, pela leitura de Heidegger. O surgimento da metafísica na Grécia, através das obras de Platão e Aristóteles, que serviram de base para as primeiras sistematizações teóricas da astrologia, é uma questão decisiva para ela. Adotando uma posição crítica, defende que a astrologia não deve ser necessariamente concebida segundo os modelos metafísicos da filosofia clássica grega, o que torna muito relevante o fato dela ter existido por milênios antes do período em que tais filósofos viveram:

O que chega desse momento, e que é muito essencial, é que você tem uma ideia de unidade do cosmos, e essa teia ou rede viva é misteriosa. A gente não consegue abarcar a origem nem a finalidade. Talvez, de alguma forma, a astrologia que eu faço tenha a ver com essa ideia, mas eu não sinto que estou retomando algo, porque esse algo me escapa, eu não sei o que é, é outro momento, outra cultura, a gente não tem como saber. O que para mim é fundamental é que tem essa ideia de unidade do cosmos, e se você não entra com a metafísica em cima, ela se torna completamente misteriosa e não cindida: o mistério em aberto que vai se fazendo no brotar do cosmos.

Camila rejeita a operação metafísica da divisão da realidade entre dois mundos: o das aparências, a que temos acesso imediato através dos sentidos do corpo, e o das essências, pensado como outro domínio que está além de nossa experiência, no qual a verdade se encontra. A propriedade ontológica de uma cisão da realidade seria responsável por encobrir um elemento essencial da astrologia: a noção de que a unidade do universo que a fundamenta é absolutamente misteriosa. Embora ela não seja orientada por nenhum paradigma existente na história da astrologia e já que diz desconhecer o que era exatamente a compreensão que havia dela antes da filosofia grega, o que importa é a ausência de uma base teórica que explica a natureza unitária do cosmos nos termos da metafísica platônica ou aristotélica. Tal elaboração filosófica teria sido capaz de desfazer o mistério e, assim, gerar uma tentativa de manipulação técnica da realidade através do conhecimento astrológico.

Outro elemento essencial do sistema que, para ela, continuou a vigorar mesmo em meio às concepções metafísicas da astrologia é o que denomina observação qualitativa, que consiste em compreender a realidade como um todo

$5 \quad$ Entrevista gravada em São Paulo, 15/06/2012. 
remetendo o observável a atributos astrológicos, um processo que se desenvolve empiricamente:

A astrologia é dada na natureza, você aprende astrologia quando olha para o céu, quando vê o vento passar, quando deixa a natureza falar. A astrologia está diretamente conectada com a natureza, com os ciclos, você pode escutar a natureza se dizendo, as estações passando, aprender o que é próprio do fogo no fogo, olhando o fogo. Quando você tem que falar de astrologia, surgem mil metáforas. Porque o fogo é isso, você olha para o fogo, ele é aquilo mesmo. A água, o ar, o vento fala, o vento me conta do ar. Quando eu falo com alguém [em cujo mapa o elemento ar predomina], ele também me conta do ar. Observando a natureza, a minha percepção qualitativa se desdobra em mil, assim como quando estou com alguém, ou diante de um evento coletivo, você vê Plutão, você vê o fogo. Você fica aprendendo astrologia com a vida. A tradição, a teoria e o conhecimento que vieram ajudam a observar, só ajudam.

Tal hierarquia em que a experiência existencial é superior à teoria depende desta concepção em que a totalidade do universo é como um grande texto, em que a multiplicidade quase inesgotável de componentes pode ser remetida a um conjunto limitado de qualidades cósmicas, permitindo que algumas partes esclareçam o sentido de outras, como as propriedades físicas do fogo revelando algo sobre atributos da personalidade humana ou sobre características de fenômenos coletivos. Essa unificação dos diversos seres e coisas através do esquema de qualidades a que os símbolos astrológicos se referem é experimentada como a expressão viva da natureza unitária do cosmos.

Dessa maneira, já que esta grande teia ou rede é concebida como observável, a teoria passa a ter um papel apenas secundário. Portanto, apesar de rejeitar tanto o modelo explicativo da causalidade quanto o das correspondências, em razão de identificar a ambos como herdeiros da metafísica, a noção de que tudo que existe está interligado bem como o uso de analogias, que permitem as metáforas, ainda são mantidos por Camila.

À noção do mistério como fundamento se articulam as de livre-arbítrio, destino e escuta:

Se a gente levar a sério mesmo o mistério, vai ter que fechar com Jung, livre-arbítrio é eu fazer com alegria aquilo que eu devo fazer, a vida se abre, ela se abre, e eu escuto, eu vou junto, mas não sou eu quem mando, isso choca com a modernidade completamente! [Para] Heidegger, tem um destinamento em curso, mas não é porque eu quero, porque eu faço, eu não abarco isso. É de uma derrota enorme para o ego! Então a gente vai indo, achando que somos nós, achando que é o que nós fazemos, que precisamos nos iluminar, e na verdade não é, é o Ser se fazendo, a gente só precisa parar, ir parando para poder ficar numa escuta, ir com ele. Você está dentro de uma tessitura que vai se desvelando na sua vida, na sua singularidade, naquele caminho vivido lá de onde você nasceu até onde você está, e o que está se abrindo e se desdobrando no tempo.

Uma mesma concepção é vista como um choque contra a modernidade e uma derrota para o ego. Trata-se de um reconhecimento de que a pessoa não 
comanda plenamente sua própria vida, pois esta está retida em um acontecimento mais abrangente. É algo paradoxal, pois é rejeitada radicalmente uma ambição de onipotência do ego, porém isto não significa um determinismo astrológico. O homem é vivido por algo maior do que ele, há um Outro que é nele. Em razão do vínculo essencial entre cada ente e a totalidade, o tempo do brotar, que abarca o ser humano em conexão com o cosmos inteiro, faz com que a relação com o todo seja constitutiva da singularidade de cada indivíduo e de seu destino, sendo ambas as coisas co-incidentes e se dando con-juntamente. A ênfase no mistério torna o pertencimento à totalidade um elemento fundamental da realidade humana, não há um protagonismo localizado no indivíduo isolado, mas uma interação com este processo de tessitura de sua existência que ultrapassa a dimensão individual. Por isso, a ação deve estar relacionada à contemplação da trajetória em que o próprio cosmos inseriu cada um e isto orienta a compreensão de si. Esta observação da vida se fazendo, que envolve uma atenção a sinais, é referida pelo termo escuta, noção que também inclui o auto-conhecimento, mas vai além deste, pois alcança questões gerais que não se limitam à experiência individual.

As alusões a Jung e Heidegger indicam características distintivas na visão de mundo e no ethos desta astróloga, mas tal influência se harmoniza com a ideia astrológica fundamental do pertencimento individual ao todo, o qual marca a caracterização da existência humana. Há uma compatibilidade que permite a assimilação, enquanto os pressupostos cosmológicos do sistema zodiacal são mantidos inalterados.

\section{Conclusão}

Ao apresentar a doutrina filosófica do neoplatônico Plotino, Bergson (2005) menciona o ponto de vista da astrologia, afirmando que ela não trata de uma influência dos astros sobre os destinos, pois o que revela é a harmonia fundamental de todas as coisas, havendo simpatia entre todas as partes do universo. É a suposição de uma conspiração de todas as coisas que faz com que um arranjo ou desarranjo que ocorre em um ponto qualquer tenha repercussão em outro ponto qualquer, ou seja, uma parte do universo é simbólica de outra. Por isso, não se trata da influência, mas de uma significação dos astros.

Tal concepção é o que Vilhena (1990) definiu como simbolismo e está na base da cosmologia dos astrólogos entrevistados, seja ela associada ao conceito junguiano de sincronicidade, enquanto próximo ou mesmo idêntico à ideia tradicional de correspondências entre os diversos domínios da realidade, ou então considerada um mistério que não se deseja explicar teoricamente. A suposição de uma harmonia fundamental de todas as coisas com a resultante 
simpatia entre todas as partes está relacionada essencialmente ao tempo que é concebido de modo qualitativo e envolve significados.

O simbolismo garante a estruturação cosmológica que possibilita abarcar as noções esotéricas, psicológicas e filosóficas acrescentadas, pois estas se articulam às categorias originariamente astrológicas para serem incluídas na prática da astrologia. Cada novo conceito assimilado amplia as possibilidades de significado e aplicação das classificações astrológicas, que passam a se referir a novos objetos e fenômenos, produzindo diferenças entre os astrólogos e transformações importantes.

Simultaneamente, os elementos novos incorporados ao sistema zodiacal recebem um sentido astrológico, ao serem inseridos no horizonte da totalidade do universo, pensado fundamentalmente de acordo com o simbolismo, premissa que perpassa concepções como sincronicidade, karma, reencarnação, projeto de vida, funções e mecanismos da psique, jogo de forças, livre-arbítrio, destino e escuta, encontradas ao longo das entrevistas. Sem dúvida, há diferenças evidentes entre os pontos de vista dos astrólogos, pois noções diversas são empregadas por cada um deles. No entanto, o sentido de todos os termos mencionados sempre depende do simbolismo na base que sustenta a astrologia e a acompanha em meio a outras variações específicas em cada cosmologia.

\section{Referências Bibliográficas}

Barros, Rui (1989). O espelho partido: astrologia \& psicopatologia: a possibilidade de diagnóstico e prevenção. São Paulo: Ágora.

Bergson, Henri (2005). Cursos sobre a filosofia grega. São Paulo: Martins Fontes.

Costa, María Elizabeth (2007). Os signos do Zodíaco como um sistema de classificação. Textos escolhidos de cultura e arte populares. Rio de Janeiro, v. 4, n. ${ }^{\circ}$ 1, pp. 39-48.

Defrance, Philippe (1972). A astrologia erudita. In: Morin, Edgar. Defrance, Philippe., Fischler, Claude. \& Petrossian, Lena. O retorno dos astrólogos: diagnóstico sociológico. Lisboa: Moraes.

Durkheim, Emile (2008). As formas elementares de vida religiosa. São Paulo: Paulus.

Durkheim, Emile \& Mauss, Marcel (1998). Algumas formas primitivas de classificação. In: RODRIGUES, J. A. (Org.) Emile Durkheim: sociologia. São Paulo: Ática.

Geertz, Clifford (1989). A interpretação das culturas. Rio de Janeiro: LTC.

Giacoia Junior, Oswaldo (2013). Heidegger urgente: introdução a um novo pensar. São Paulo: Três Estrelas.

Lévi-Strauss, Claude (1989). O Pensamento Selvagem. Campinas: Papirus.

Lévi-Strauss, Claude (1980). Totemismo hoje. Os Pensadores. São Paulo: Abril Cultural. 
Magnani, José Guilherme (1999). Mystica Urbe: um estudo antropológico sobre o circuito neo-esotérico na metrópole. São Paulo: Studio Nobel.

MARTINS, Roberto (1995). A influência de Aristóteles na obra astrológica de Ptolomeu (O Tetrabiblos). Trans/Form/Ação. São Paulo, 18: 51-78.

Morin, Edgar, Defrance, Philippe, Fischler, Claude \& Petrossian, Lena (1972). O retorno dos astrólogos: diagnóstico sociológico. Lisboa: Moraes.

Pinheiro, Marcus. Determinismo, liberdade e astrologia nos Estóicos. História, imagem e narrativas. $\mathrm{N}^{\circ}$ 10. Abril / 2010.

Rapport, Nigel \& Overing, Joanna (2000). Social and Cultural Anthropology: the key concepts. New York: Routledge.

Van De Beuque, Guy (2004). Experiência do nada como princípio do mundo. Rio de Janeiro: Mauad.

Vilhena, Luíz Rodolfo (1990). O mundo da astrologia: estudo antropológico. Rio de Janeiro: Jorge Zahar.

Viveiros De Castro, Eduardo (1996). Cosmologia. In: BONTE, P. \& IZARD, M. (Org.) Diccionario de Etnología y Antropología. Madrid: Akal. 
